\title{
Der Berg kreißte - gebar er eine Maus? Europa vor dem Bundesverfassungsgericht
}

\author{
CHRISTIAN JOERGES ${ }^{\circ}$
}

$D^{\circ}$ as Bundesverfassungsgericht (BVG) ist immer wieder zu einem Forum für die Auseinandersetzung mit Grundsatzfragen der Europäischen Wirtschaftsverfassung geworden. Seine Urteile und Beschlüsse werden weithin aufmerksam beobachtet. Vor dem jüngsten Urteil zu Europäischem Stabilitätsmechanismus (ESM) und Fiskalpakt hatte sich dies zur Aufgeregtheit gesteigert: in Deutschland, weil dessen finanzielle Verstrickungen im Verlauf der Eurokrise immer größer und unübersichtlicher werden, in anderen Ländern, weil man nicht einsehen will, dass das deutsche BVG mit faktisch gesamteuropäischer Wirkung judiziert.

Um solche Hoffnungen und Ängste beurteilen zu können, muss man den Kontext bedenken, in dem das Gericht operiert. In der Union ist binnen zwei Jahren ein Regelwerk erstellt worden, das alles wirtschaftsund sozialpolitische Handeln in Europa neu programmiert. Der letzte Baustein war der Fiskalpakt vom März 2012 und sein Gebot der Einführung nationaler Schuldenbremsen. Er ergänzt das zuvor beschlossene Verfahren zur Vermeidung und Korrektur makroökonomischer Ungleichgewichte, das der Kommission die Beaufsichtigung der Wirtschafts- und Sozialpolitik aller Mitgliedstaaten ermöglicht. Jürgen Habermas hat dafür das Wort vom „Exekutivföderalismus“ in Umlauf gebracht. Dessen Inhalte sind vorbestimmt: Wechselkursanpassungen sowie eine autonome Zinsund Fiskalpolitik gibt es nämlich in der Eurozone nicht. Einzig mit ihrer Lohn- und Beschäftigungspolitik sowie mit Begrenzungen von Sozialleistungen können die Mitgliedstaaten den Geboten einer strikten Stabilitätspolitik genügen. Was bleibt, ist der Vorrang einer strikten Finanzstabilität. Damit ist die EU zur „Austeritätsgemeinschaft“ mutiert, die heftige soziale Unruhen provoziert - und den Friedensnobelpreis empfängt.

Dies alles bildet den Hintergrund, nicht etwa den Gegenstand, des Urteils vom 12. September. Das BVG hat sich dort nur auf einen Baustein des neuen Regelungskomplexes konzentriert, freilich einen wichtigen: die Budgethoheit des Parlaments, ein unverfügbares Kernstück demokratischen Regierens. Nun hat das Grundgesetz durch die Schuldenbremse diese Autonomie "fühlbar" beschränkt. Dies hat das BVG als „nicht von vornherein demokratiewidrig" erklärt und als Akt der Zukunftssicherung abgesegnet. Umso intensiver hat es die finanziellen Bindungen und Risiken, die Deutschland mit dem ESM eingegangen ist, in Augenschein genommen. Es hat sie im Ergebnis gebilligt, freilich unter Bedingungen. Zum einen seien die Verpflichtungen der Bundesrepublik der Höhe nach auf 190 Mrd. € begrenzt, zum anderen sei das deutsche Mitglied im ESM-Rat dem Bundestag zur Auskunft verpflichtet. Beides müsse Deutschland völkerrechtlich verbindlich klarstellen.

Mit seiner zur Routine gewordenen Ja-Aber-Argumentation hat das Gericht die Wende zur „Europäischen Wirtschaftsregierung“ nicht blo- ckiert, aber immerhin wichtige Prinzipien in Erinnerung gebracht. Diese Form richterlicher Achtung des Primats der Politik hat viel Beifall gefunden, der dem BVG nach der fulminanten Schelte des Lissabon-Urteils von 2009 gut getan haben mag. Hat das Lissabon-Urteil diese Schelte, hat das neue Urteil diesen Beifall wirklich verdient? Mitnichten, will mir scheinen. Im Lissabon-Urteil hat das Gericht das Theorem der „Integrationsverantwortung" kreiert: Zwischen Integration und Demokratie bestehe ein Spannungsverhältnis, und es sei die Aufgabe des Gerichts, darauf hinzuwirken, dass die Demokratie beim Integrationsfortschritt nicht auf der Strecke bleibt. Es war nur folgerichtig, hier die Budgetautonomie in Anschlag zu bringen. Aber dies ist nun leider in betrüblicher Einseitigkeit geschehen: „Da der Bundestag durch seine Zustimmung zu Stabilitätshilfen den verfassungsrechtlich gebotenen Einfluss ausüben und Höhe, Konditionalität und Dauer der Stabilitätshilfen zugunsten hilfesuchender Mitgliedstaaten mitbestimmen kann, legt er selbst die wichtigste Grundlage für später möglicherweise erfolgende Kapitalabrufe". Das Deutsch ist schwierig, die Botschaft aber klar: Die Beschränkung der Budgetautonomie anderer Mitgliedstaaten, die mit der Konditionierung von Leistungen verbunden ist, braucht den Bundestag nicht zu bekümmern. Die Wahrung der Budgethoheit des Bundestages wird damit durch eine Beschneidung des Handlungsspielraumes der Regierungen und Parlamente der Empfängerländer erkauft. Deutschland ist aber Mitgliedstaat einer Union, in der ein Budgetrecht allen nationalen Parlamenten zusteht. Dieses gemeineuropäische Recht zu achten, gehört zur Integrationsverantwortung Deutschlands.

So groß, wie es in den Beifallsbekundungen erscheint, war die Zurückhaltung des BVG also keineswegs. Richtig bleibt, dass es das gesamte Gebäude des Euroraumes vor dem Einsturz bewahrt hat. Die Verantwortung für den Einsturz durfte das BVG nicht auf sich nehmen, weil es nicht zum Richter über die EU als Ganze berufen ist. Sehr wohl aber kann und soll es seine "Integrationsverantwortung" als Mandat zur Verteidigung der Integrität des Integrationsprozesses als Ganzem verstehen und wahrnehmen. Der Aufgabe, die Erfordernisse eines „europäischen Demokratienverbundes" zu formulieren, hat das BVG sich nicht gestellt.

Alle hier behandelten Themen bespreche ich ständig und intensiv mit meinem Kollegen Josef Falke. Dieser Austausch hat seine Spuren in dem Text hinterlassen, für dessen Unzulänglichkeiten ich allein verantwortlich bin.

CHRISTIAN JOERGES, Prof. Dr., forscht am Zentrum für Europäische Rechtspolitik an der Universität Bremen.

christian.joerges@sfb597.uni-bremen.de 